\title{
The Effectiveness of Extracorporeal Shock Wave Therapy to Reduce Spasticity of Lower Limb for Post-Stroke Patients: A Systematic Review
}

Rosa Cabanas-Valdés (PhD), Jordi Calvo-Sanz (PhD), Ana Germán-Romero (PhD)

Faculty of Medicine and Health Sciences, department of Physiotherapy. Barcelona, Catalonia, Spain Universitat Internacional de Catalunya.

BACKGROUND: Recent studies indicate that extracorporeal shock wave therapy (ESWT) is being considered as a new treatment method for spasticity. ESWT is a non-invasive technique where high-energy acoustic impulses produced by different types of generators cause a mechanical stimulus to trigger a chemical reaction (mechanotransduction) in the tissues (Ogden et al., 2001).

OBJECTIVE: To establish if ESWT can improve spasticity and different functional outcomes in post-stroke patients.

METHODS: CENTRAL, MEDLINE, CINAHL, PEDro, REHABDATA, Scielo, Scopus, Web of Science, Trip Database, and Epistemonikos were searched and reference lists screened to identify clinical trials (randomized and nonrandomized) of ESWT, in stroke survivors published until April 2018. Two reviewers independently screened references, selected relevant studies, extracted data, and assessed trial quality. The primary outcome was spasticity and secondary outcomes were range of motion (ROM), pain and gait. Quality of articles was evaluated by PEDro scale/(Maher et al., 2003).

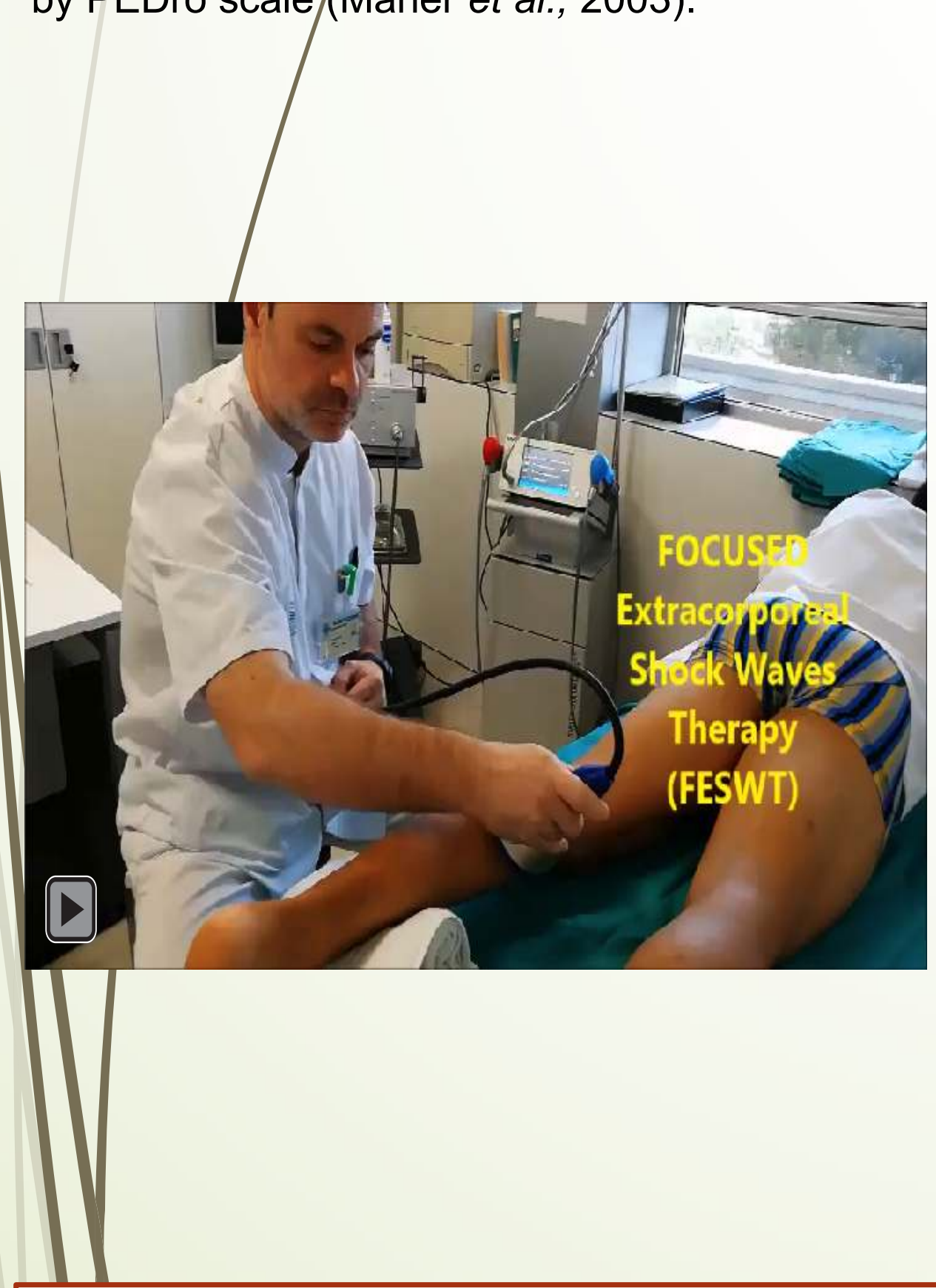

Mean difference analysis of spasticity outcome by RevMan 5.3: pre-post intervention (above) and between-group (bottom)

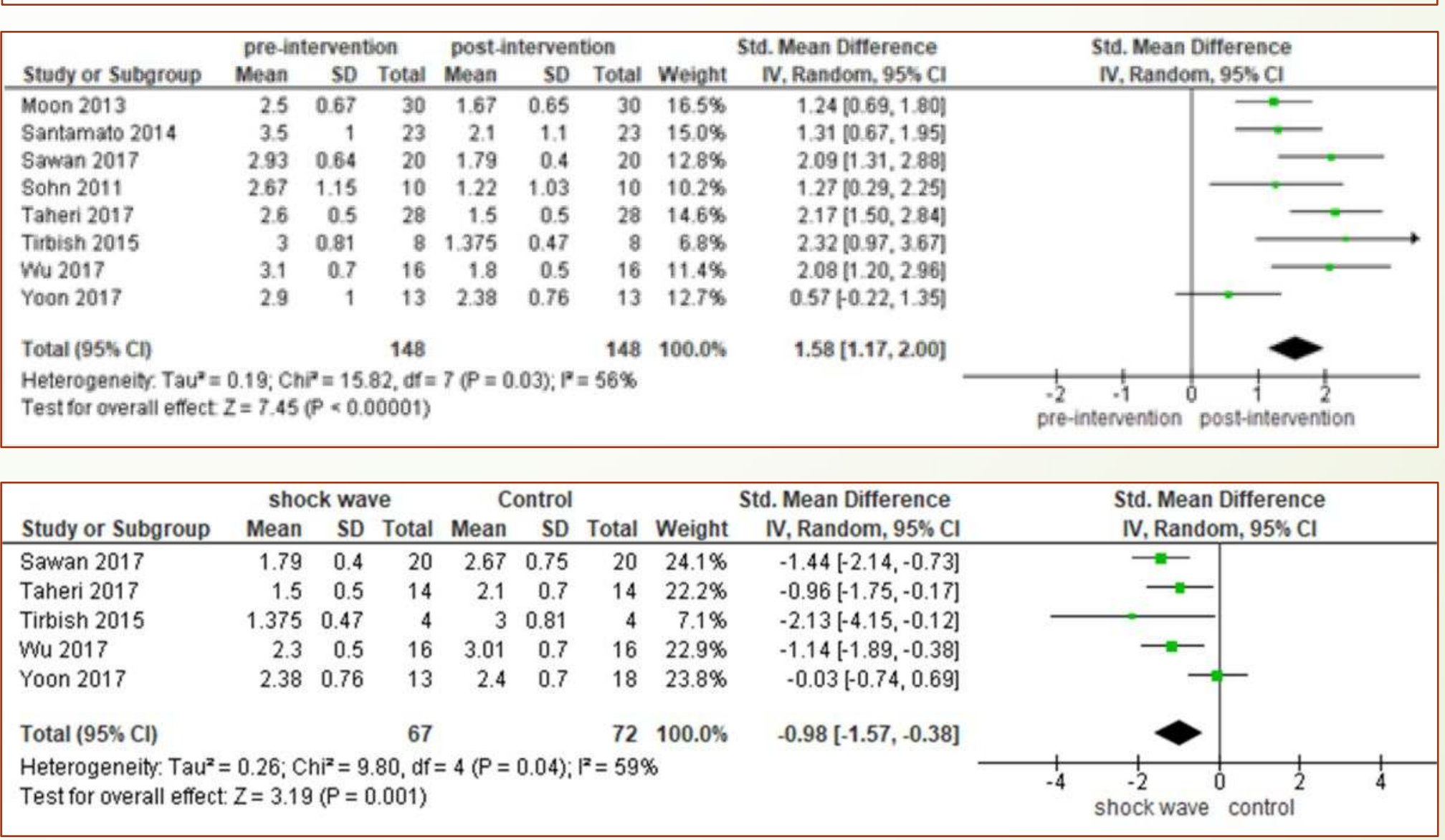

CONCLUSIONS: Radial ESWT has been suggested to be a novel and effective method for improving spasticity in patients with stroke. ESWT reduces spasticity and increases range of motion, pain and gait; no adverse effects had been observed. Nonetheless, these results must be taken with caution, as there are few studies and five had no control group.

RESULTS: 10 studies were included, 5 of which were randomized controlled trial. Methodological quality was moderate 5,4/11 points in PEDro scale.

A total of $255(13,08)$ participants were analyzed, mean age of 54 '4 years and 176 were male. Targeted muscle was gastrocnemius in the majority of studies. ESWT main features were: frequency $(4-10 \mathrm{~Hz})$, energy $\left(0,03-0,3 \mathrm{~mJ} / \mathrm{mm}^{2}\right)$, shots (1500-3000), sessions (1-6), one session per week.

Spasticity, evaluated by MAS, was reduced $(0,57-2,32)$ points in all studies.

\begin{tabular}{|c|c|c|c|c|}
\hline \multirow[t]{2}{*}{ Studies } & \multicolumn{4}{|c|}{ Outcomes } \\
\hline & Spasticity & ROM & Pain & Gait \\
\hline Sohn et al., 2011 & YES $^{a}$ & & YES $^{a}$ & \\
\hline Moon et al., 2013 & YES $^{a}$ & $\mathrm{NO}$ & & \\
\hline Santamato et al., 2014 & YESa & YES $^{a}$ & & \\
\hline Tirbisch et al., 2015 & YES $^{a}$ & & & \\
\hline Ratsgoo et al., 2016 & $\mathrm{YES}^{\mathrm{b}}$ & YES $^{b}$ & $\mathrm{YES}^{\mathrm{b}}$ & $\mathrm{YES}^{\mathrm{b}}$ \\
\hline Taheri et al., 2017 & YES $^{b}$ & YES $^{b}$ & YES $^{b}$ & $\mathrm{YES}^{b}$ \\
\hline Wu et al., 2017 & YES $^{a}$ & $\mathrm{YES}^{\mathrm{b}}$ & & $\mathrm{NO}$ \\
\hline Yoon et al., 2017 & $\mathrm{YES}^{\mathrm{b}}$ & & & \\
\hline Radinmher et al., 2017 & YES $^{b}$ & YES $^{b}$ & & $\mathrm{YES}^{\mathrm{b}}$ \\
\hline Sawan et al., 2017 & $\mathrm{YES}^{\mathrm{b}}$ & YES $^{b}$ & & $\mathrm{YES}^{\mathrm{b}}$ \\
\hline $\begin{array}{l}\text { a: with-in-group significati } \\
\text { b: bewteen-group significe }\end{array}$ & ences ( & $<0.05)$ & & \\
\hline
\end{tabular}

